\title{
MEDIO SIGLO DE ENSAYO NICARAGÜENSE
}

\author{
POR \\ FIDEL COLOMA GONZALEZ \\ UNAN
}

Ubicamos este medio siglo entre 1927 y 1977 . Lapso históricamente muy complejo, obliga a buscar un principio ordenador de la exposición. Recordable es la tripartición que acepta en el desarrollo del capitalismo occidental Lucien Goldmann: capitalismo de organización o sociedad de masas, hasta alrededor de los setenta ${ }^{1}$. Según él, caracterizan a cada etapa rasgos específicos en marcos dentro de los cuales se correlaciona lo económico-social con lo cultural y lo propiamente artístico y literario. Sin tener en cuenta las críticas apuntadas al estructuralismo genético de Goldmann ${ }^{2}$ encontramos que es muy difícil aplicar sus categorias al desarrollo histórico y literario de Nicaragua; en cambio, nos encontramos con un país dependiente, frustrado en su lucha por desarrollar su revolución liberal burguesa, sometido a la intervención de un poder hegemónico extranjero. Esto se refracta en un panorama cultural de cierta complejidad, en el cual se entreveran formas coloniales y aún feudales de vida, con expresiones de modernidad en ciertos aspectos de lo artístico y cultural y de la ciencia y la tecnología.

Es ésta una dificultad teórica mayúscula para la historia literaria del país. Problema del cual hay conciencia. Así, por ejemplo, Jorge Eduardo Arellano afirma la necesidad de una periodización:

El criterio para elaborar esta periodización (se refiere a la del desarrollo literario) debe tomar en cuenta la correlación entre los procesos literarios y los históricos, como también la interrelación entre los sistemas políticos y la producción literaria ${ }^{3}$.

Desgraciadamente -itodavía hoy!-, esto no pasa de una aspiración. Esperamos los aportes del propio Arellano y de otros jóvenes investigadores que surgen como alentadoras promesas.

\footnotetext{
${ }^{1}$ Lucien Goldmann, La création culturelle dans la societé moderne (Paris, 1971), 47 y s. ${ }^{2}$ Marc Zimmerman, Lucien Goldmann: el estructuralismo genético y la creación cultural (Minneapolis, 1985), 70 y s.

${ }^{3}$ Jorge Eduardo Arellano, "Periodos literarios en Nicaragua", (Managua: Ventana, 1982), y La Brújula 11 (México, julio 1983): 12. Cito por esta edición.
} 
En un trabajo temprano sobre la narrativa de Adolfo Calero Orozco ${ }^{4}$, intentamos aplicar el método generacional a la periodización del desarrollo literario nicaragüense a partir del 900. Partiendo de las ideas de Portuondo ${ }^{5}$, aceptamos su generación de 1910-1939, a la que caracteriza como la del "populismo y del purismo". Para este autor, una generación literaria se constituye en un período de treinta años.

Las características tan peculiares del desarrollo histórico, cultural y literario de Nicaragua en el presente siglo, no permitieron una descripción adecuada dentro del marco propuesto por Portuondo. Tuvimos que establecer dentro de ese amplio periodo de 1910-1939, varias promociones u oleadas, que terminaron, por fin, por quebrar los límites temporales que primitivamente nos habíamos impuesto. Así, tuvimos que reconocer: un primer grupo, que aparece entre 1910-1925, que corresponde a la que Zepeda-Henríquez $z^{6}$, llama generación del 27; un segundo grupo, que aparece por los años 30, denominado por ZepedaHenríquez "generación de vanguardia y post-vanguardia"; y una tercera, integrada por Ernesto Cardenal, Ernesto Mejía Sánchez, Guillermo Rothschuh Tablada, etc., que coincide con la "generación de 1957" de Zepeda-Henríquez.

El propio material histórico nos obligó, pues, a establecer promociones de extensión más breve (quince años). Una de las características del sucederse de estas generaciones es que se imbrican, en determinados momentos coinciden y, aún perteneciendo a distintas tiendas ideológicas, colaboran en empresas literarias comunes. Fenómeno que da a veces al proceso literario nicaragüense, por lo menos en ciertos niveles, la cadencia de una tradición artesanal en la cual maestros, oficiales y aprendices, se transmiten y ejercitan en comunidad sus saberes.

Cuando se habla de generaciones en historia literaria el término resulta ambiguo. Muchas veces se le hace sinónimo de período literario y aún de período histórico, a secas. Estrictamente, cuando hablamos de generación literaria, nos referimos a:

${ }^{4}$ Fidel Coloma González, "Notas al arte narrativo de Adolfo Calero Orozco", (Managua: Ciencias de la Educacion 1, y Academia Nicaragüense de la Lengua, 1966). Cito por esta última.

5 José Antonio Portuondo, La hisloria y las generaciones (Santiago de Cuba, 1958), 100. Ver además: "Las generaciones literarias cubanas. El problema de las generaciones", en Capttulos de literatura cubana (La Habana, 1981), 19 y s.

6 Eduardo Zepeda-Henríquez, "Teoría y aplicación del método generacional en Nicaragua",(Managua: Revistadel Pensamiento Centroamericano 188-189, julio-diciembre 1985). Distingue las siguientes generaciones a partir de la de Dario: 1890-1904 (Generación modernista y de Darío, o de 1897); 1905-1919 (Segundo modernismo nicaragüense o generación de 1912); 1920-1934 (Generación post-modernista o de 1927); 1936-1949 (Generación de vanguardia y post-vanguardia o de 1942; 1950-1964 (Generación heredera por excelencia y, por lo mismo, de tipo "renacentista" o de 1957); 1965-1979 (Ultima generación que se ha definido por completo y que ya ha empezado a ser "gestora" o de 1972): 16. 
... aquel grupo de individuos contemporáneos que, surgidos en circunstancias naturales y sociales comunes, participan de una mundividencia y de un lenguaje análogos?.

De suerte que, en un mismo período histórico, pueden coincidir, y de hecho coinciden, generaciones que son coetáneas -o sea, pertenecen a la misma zona de fechas - y contemporáneas, -vale decir que, perteneciendo a diferentes zonas de fechas, conviven en un mismo tiempo histórico. Esta coexistencia puede traducirse en asociación, como hemos señalado antes, pero también en rivalidad, en lucha franca.

Lo importante, en última instancia, es el período histórico, la manera cómo los diversos elementos sociales se estructuran, formando una configuración característica. Según Zimmerman, que resume el pensamiento de Goldmann, la tarea del investigador consiste en:

Establecer las unidades comparativas de análisis: hallar los elementos característicos del capitalismo y ver como se agrupan en patrones estructurales relativamente estables, cuyos promedios de duración constituyen los períodos y tendencias más destacados de $\mathbf{l}^{\mathrm{B}}$.

Esto permitiría efectuar ciertos cortes en el desarrollo histórico, constituyendo los períodos, las zonas dinámicas separadas por esos cortes. Como dijimos, no se ha realizado, en forma sistemática, la aplicación de estos criterios a la historia literaria de Nicaragua.

Tendremos que basarnos en criterios intuitivos de tanteos, en los cuales estaremos aludiendo a períodos y dentro de ellos a promociones o generaciones, como otros críticos las llaman. En algunos casos, el nombre de una generación o grupo literario, por convención, denomina al sub-período histórico en que se ubica, aún a sabiendas de que existen, o existieron, otros grupos que la adversaban'. A medida que nos aproximamos a los casos concretos, la red de interrelaciones se hace más compleja. Por ejemplo, puede haber entre los grupos comunidad de ideales literarios, pero diferencias muy marcadas en lo político ${ }^{10}$.

Se nos perdonarán estas explicaciones. Pero, siendo el ensayo el género ideológico por excelencia, es decir, aquél en el cual se expresan las ideas de un

\footnotetext{
${ }^{7}$ Portuondo, "Las generaciones literarias cubanas. El problema de las generaciones", op. cit, 24-25.

${ }^{8}$ Zimmerman, op cit, 50.

"Asi ocurre con la llamada "generación de vanguardia" a la cual se oponen, por ejemplo, el grupo PROA, de León, y las agrupaciones político-literarias integradas por obreros de Managua.

10 Julio Valle Castillo aplica estos criterios en su ensayo "Cabrales: ide6́logo del movimiento de Vanguardia”, (Managua: Nuevo Amanecer Cultural, 448, febrero 4, 1989) al que tendremos que referirnos más adelante.
} 
autor, de una clase o fracción de clase, de una generación o de un movimiento, respecto a los problemas que le plantea el mundo en torno, se hace imperativo ofrecer, siquiera en forma esquemática, un cuadro de ese mundo históricosocial.

En los cincuenta años que reseñamos, podrían establecerse estas etapas: 1927-1934. En este período lo decisivo es la lucha que sostiene el general César Augusto Sandino contra la intervención norteamericana. Los escritores, intelectuales y políticos de todos los niveles sociales se hallan enfrentados a una decisión crucial: apoyar a Sandino en su lucha libertaria, o combatirla, lo que equivalía a aliarse con los invasores, o mantener una posición neutral, con variados matices de inclinación a uno u otro bando. Es importante, además, tener en cuenta que la guerra sandinista afectó a toda la vida nacional y a todas las clases, aunque fue principalmente una guerra campesina. Sin embargo, miembros de todas las clases lo apoyaron. $Y$ no fueron raras las señoras y señoritas de la mejor sociedad que pertenecieron al "servicio secreto" del ejército sandinista ${ }^{11}$. Este periodo termina con la salida de las tropas extranjeras (1933) y el asesinato del general Sandino (1934).

En un segundo período (1934-1979) lo decisivo es la lucha contra el poder del general Anastasio Somoza García, su familia y los grupos de sus allegados. Pueden distinguirise dos momentos: uno que termina en 1956, con la muerte del general Somoza García, que marca ciertos cambios en los procesos políticos y sociales del país. Y otro, que podría ubicarse en torno a los años 60 . que es cuando se define el grupo revolucionario (FSLN), que llegará, después de casi un cuarto de siglo de lucha, hasta el triunfo de 1979.

Tendríamos, así, el siguiente "mapa" de períodos y generaciones o grupos en estos cincuenta años:

PERIODOS

$1927-1934$

C.927-1934

$1934-1979$

1934-1956

$1956-1977$
GENERACIONES

Generación del 27

Generación de vanguardia (se inicia). grupos literarios formados por obreros de Managua.

Generación de vanguardia. Grupo PROA,

Generación de 1957

Generación de 1972

\footnotetext{
${ }^{11}$ Ver: José Román, Maldito Pats (Managua, 1979), 136 y s.
} 
Usamos, como se ha visto, la terminología que emplea Zepeda-Henríquez en la obra ya citada, la que iremos adaptando a las necesidades de nuestra exposición. Las generaciones que se incorporan a la vida nacional en cada uno de esos períodos y sub-períodos se enfrentan a desafíos específicos; sin embargo, pueden darse, aunque sea en lo referente al ensayo, características generales que afectan a la producción ensayística del medio siglo.

Si partimos de la generación llamada del 27, que es la de Augusto C. Sandino (1895-1934), vemos que su lucha contra la intervención extranjera planteó graves problemas morales, políticos y de teoría socio-cultural, a ésta y a las siguientes generaciones. Y todos problemas de gran trascendencia. Era urgente definir los caracteres de la cultura (y del ser) nacional, como una manera de defender su identidad, amagada por una ocupación que se prolongó por décadas. Era indispensable una búsqueda de valores originales, sobre los cuales asentar una conducta privada y una acción colectiva. Todos los aspectos de la vida estaban -ya lo dijimos- penetrados por esa preocupación, no sólo lo socio-político, sino también lo religioso y lo estético. Gradualmente los intelectuales se vieron llevados a un enjuiciamiento general de la cultura nacional.

Puede decirse que el antiimperialismo, interpretado por cada uno a su manera, es característica general en la evolución de las letras nicaragüenses y, en especial, de la mayoría de estos pensadores. Afirma Jorge Eduardo Arellano:

Al replantear los hitos que ha marcado la evolución creadora en Nicaragua, es imprescindible identificar también nuestras tendencias literarias como nuestras mejores tradiciones culturales, sobre todo con una de las más auténticas de nuestra historia, el anti-imperialismo. [...] El anti-imperialismo [...] fue determinante en la conformación de la conciencia nacional, en la existencia del patriotismo nicaragüense...

Los movimientos antiimperialistas se enfrentan, a través de la historia del país, con los grupos cuyos intereses los mueven a aliarse con los norteamericanos y a propiciar su intervención. Esa dialéctica dinamiza desde el siglo pasado la historia nacional.

En política, algunos rechazaron a los partidos tradicionales (liberales y conservadores) a quienes acusaban de haber llevado el país al estado desastroso en que se encontraba. No pocos buscaron la salida en un "hombre fuerte", en una especie de déspota ilustrado, que gobernara por encima de las facciones. Otros quisieron renovar las viejas cepas partidarias, manteniéndose dentro de sus cuadros. Hubo quienes intentaron modernizar las doctrinas, alzándolas por encima del antagonismo ya secular de conservadores y liberales. Este esfuerzo de los intelectuales, desembocará en nuevas vías políticas: en tempranos movimientos anarquistas, laboristas y socialistas, en un movimiento fascista (1934), en un posterior social-cristianismo y, a partir de 1959-60, en el Frente Sandinista de Liberación Nacional. Sin mencionar diversas tendencias, algunas 
de vida efímera, desprendidas de los troncos partidarios tradicionales. Lo importante es tener presente que casi toda, por no decir toda, la actividad ensayística del medio siglo se enmarca dentro de idearios políticos. Teniendo este otro aspecto en cuenta: la mayoría de los escritores de ensayos tuvieron, o tienen, participación directa en la política. No se limitaron a la teoria: han ido a la práctica.

Esto lleva a destacar otro rasgo de estos ensayos: su carácter periodístico. Destinados al diario o a la revista, buscan persuadir al lector, convencerlo. Son ensayos polémicos. Muchos son irónicos, humorísticos; por eso se refugian en revistas de circulación masiva como La Semana Cómica. Entre risas y veras trasmiten su mensaje: Joaquín Pasos, Manolo Cuadra, por ejemplo. De forma que existe una abundante literatura ensayística desparramada en hojas periódicas. Son escasos los escritores que han recogido sus ensayos en libros. $\mathrm{Y}$ cuando lo han hecho, como es el caso de Pablo Antonio Cuadra, su gran volumen les ha impedido recogerlos todos. Otras veces, por razones de lucha revolucionaria (FSLN), los trabajos de sus dirigentes se han impreso en hojas mimeografiadas, lo que ha ocasionado la pérdida de parte de ellos.

Teñido de periodismo, cuando no de oratoria proselitista, el ensayo recurre a la descripción, a la anécdota, al chiste, a la sátira, a la parodia, a la ironía, al humor, al estilo epistolar, a la biografía, a la autobiografía y al aforismo. Todos los temas tratan, no sólo el literario. No es excederse decir que la literatura nicaragüense de este medio siglo, salvo contadas excepciones, entre las cuales la más saliente es Carlos Martínez Rivas, está penetrada de ensayismo. Esto se observa claramente a partir de los años 60 , cuando se intensifica la lucha política contra el régimen de Somoza.

La variedad de formas y temas que presenta el ensayo, las interrelaciones constantes entre política y literatura (y cul tura, en general) lollevan a confundirse muchas veces con la crónica y el artículo periodístico. Incluso hay ensayistas que son periodistas en ejercicio permanente. Por ejemplo, Pedro Joaquín Chamorro (1924-1978), director de La Prensa, que mantuvo una columna editorial diaria en su periódico por más de veinte años.

Todas estas reflexiones y algunos hechos nos llevan a establecer los límites y la metodología de este trabajo. Uno de los hechos: no existe una historia del ensayo nicaragüense. Además, son escasos los autores que han recogido en libro su obra ensayística. Esto nos obliga a seguir un criterio de "muestreo", no sólo de autores (habrá autores de ensayos notables que no tratan, sea por ignorancia, sea por inaccesibilidad de las fuentes), sino también, dentro de la obra de los propios autores estudiados. Algunos tienen obra tan caudalosa (Pablo Antonio Cuadra, Jorge Eduardo Arellano), que es imposible captar todos sus aspectos en este trabajo. Nos reduciremos a las líneas generales más salientes. Esto explica que demos mayor importancia al contenido, a la historia de las ideas en torno a grandes problemas, que a la evolución de las formas y estilos. Imposible, por 
ahora, por lomenos para mí, intentar algo como lo que Robb hizo magistralmente en El estilo de Alfonso Reyes ${ }^{12}$.

Ahora, en cuanto al "medio siglo". Tomamos el lapso que va desde 1927 a 1977. O sea, desde el $1^{\circ}$ de julio de 1927, que es cuando Sandino firma su Manifiesto en el mineral de San Albino, en el cual expone sus razones para levantarse en armas contra la ocupación militar norteamericana, hasta los prenuncios de la caída del régimen somocista. Dejamos fuera el período que se inicia en julio de 1979 y llega hasta el presente, primero porque nos sería imposible manejar y exponer la abundantísima bibliografía que ha generado la Revolución, y después, porque este decenio posee características propias, que ameritan su estudio con enfoque unitario en un trabajo independiente. Sin embargo, por las razones que en cada caso se explicarán, se tendrá que mencionar la obra de algunos de estos autores, principalmente Carlos Fonseca. Dicho esto, vamos al grano.

\section{Generación del 27}

Formada por los que ingresan decisivamente en la vida nacional en torno a los años 1927-1934. Son los coetáneos de Sandino. Es una promoción brillante en la cual figuran, être otros, Salomón de la Selva (1893-1959), Edelweis Torres (1898) y Luis Alberto Cabrales (1901-1974), éste último el más joven del grupo y que más bien se integra a la generación siguiente, de la cual es uno de los mentores. Los sucesos generacionales decisivos fueron la ocupación norteamericana y la lucha de Sandino.

Fue una generación combativa. Algunos de ellos se formaron en el extranjero: Salomón de la Selva, en los Estados Unidos; Edelberto Torres, en Guatemala; Luis Alberto Cabrales, en Francia. Con grandes diferencias políticas entre ellos, todos manifiestan un acendrado nacionalismo. Carlos Fonseca describe así la actitud generacional de la que él llama Generación de 1926:

La generación de 1926 es la que en la historia de Nicaragua ha dado mejores demostraciones de combatividad y fue alli que surgió Sandino y su glorioso Ejército Defensor de la Soberanfa Nacional. El movimiento nacional encabezado por ese ejército es el movimiento más poderoso que ha surgido en la historia del país para enfrentarse a los partidos liberal y conservador ${ }^{13}$.

Los años de formación de esta generación son duros: Asisten a la caída de Zelaya, al triunfo de la revolución libero-conservadora, que se transforma en régimen conservador. Las medidas económicas adoptadas bajo los dictados del

12 James Willis Robb, El estilo de Alfonso Reyes (Imagen y estructura), (México, 1978).

${ }^{13}$ Carlos Fonseca, Obras, T.1, Bajo las banderas del sandinismo, (Managua, 1982) 37. 
gobierno americano y de los banqueros neoyorquinos significan el traspaso de la riqueza - y de la soberanía - nacional al extranjero: las aduanas, el ferrocarril, el Banco Nacional, todo queda intervenido. Cruentas guerras y represiones destruyen la riqueza, pública y privada, en Chinandega, León, o Masaya. Esto antes, como decimos, de la guerra sandinista que se inicia en 1926-27.

En el plano literario (se los califica de post-modernistas) los escritores se acogen a los periódicos y a las revistas literarias. Entre éstas, la más influyente es Los Domingos (1918-1924). Un editorial nos describe así el ambiente literario a que estos jóvenes se incorporan. Describe a los escritores:

Cohibidos por el ambiente, embotados por la política, entumecidos por el diarismo, menospreciados por la pobreza, pasan su vida entre ensueño y ensueño sin hacer nada serio, sin emprender la obra que ellos podrían realizar, sin encontrar la mano que los conduzca por el camino de la tranquilidad y el estudio. Pasan su vida así, leyendo revistas y diarios y de cuando en vez, los escasos libros de importancia que suelen caer por milagro en las librerías. Pasan su vida asi, luchando por no caer en la astrosa bohemia, en la triste miseria que hace genios a algunos y pordioseros a muchos ${ }^{14}$.

Es un buen diagnóstico de la anemia espiritual que sufre el país -que ha producido a Rubén Darío-, y también de la indefinición ideológica de estos intelectuales, que terminan el mencionado editorial solicitando la ayuda del gobierno para los escritores. En otro editorial declaran que anhelan terminen en Nicaragua,

esas escenas de violencia, casi siempre producto de la equivocacion, cuando no de la injusticia. No queremos, ni revoluciones, ni prisiones. Queremos libertad, derechos y garantías para todos ${ }^{15}$.

Es lógico que su voz suene asordinada, viven en pleno período intervencionista. Sin embargo, cuánta rebeldía se acumula en el corazón valiente de un Edelberto Torres o de un Salomón de la Selva. O en el de Sandino.

SALOMON DE LA SELVA (1893-1959).

Convergen en esta personalidad - impar en las letras hispanoamericanaslas culturas hispánicas, renovadas por el modernismo (nunca dejó de venerar a Dario), las anglosajonas, particularmente en sus formas norteamericanas (fue poeta excelente en inglés) y la herencia clásica greco-latina que conocía con intimidad rara en nuestros tiempos. Sus ideales humanistas, liberales,

14 "Incuria literaria", (junio 20, 1920). En Coloma, op.cit., p. 14, nota 1

${ }^{16}$ Editorial del 2 de abril de 1922, op. cit, 14-15. 
individualistas, lo llevan a rechazar la intromisión imperial norteamericana, contra la cual mantuvo una sostenida campaña. Sandinista de la primera hora, se había destacado por su activa dirigencia en los medios laborales del país y por sus polémicas colaboraciones periodísticas. No tenía pelos en la lengua. Sostenía que el imperialismo foráneo se apoyaba en un imperialismo interno detentado por una oligarquía criolla, estéril, incapaz de explotar la riqueza del país, que sometía al pueblo a niveles de miseria y lo obligaba a emigrar ${ }^{16}$. Creía necesario dotar a la familia campesina de parcela propia, darle asistencia técnica, herramientas, capital de trabajo. Este especial sesgo de su pensamiento lo aparta de los extremismos, de izquierda y derecha. Fue anticomunista y antifacista. Después del asesinato de Sandino y de su retiro a México (1935) se apartó, al parecer, de las luchas políticas. No volvió sino esporádicamente a su patria, de la cual había sido exiliado. Al fin, apoyaba una especie de "democracia dirigida", cuyos grupos mandantes seleccionaran los pre-candidatos entre los cuales elegirían las masas. Algo así, aunque no idéntico, a lo que practica el PRI mexicano ${ }^{17}$.

La prosa de SS es lapidaria, casi aforística. Su estilo, claro, elegante, preciso. Su ideal es clásico en todo. "Llamar claramente las cosas - dice-es una manera de entenderlas"18. Su pensamiento no vacila, se diversifica lógicamente en ideas menores, todas las cuales confluyen, armónicamente, al concepto central. Da la impresión de que puede decir todo, o hacer lo que quiera con el lenguaje. Véase un ejemplo de su estilo periodístico. Respalda la campaña de Sandino para que el pueblo no vote en las elecciones de 1928:

Votar por Benard, o por Moncada, equivale a confirmar el derecho que Moncada y Benard le han reconocido al yanqui para acabar a sangre y fuego con los patriotas. Si el pueblo cree en Sandino, no debe votar. Un voto es más mortal para la patria, ya sea dado por Moncada, ya por Benard, que una bala disparada contra Sandino ${ }^{19}$.

Su visión greco-latina del mundo lo lleva a presentar sus ideas en forma "ejemplar" encarnada en figuras históricas, o fantásticas, modélicas. Así sus grandes poemas Evocación de Horacio (1949) Evocación de Píndaro (1957). Así

${ }^{16}$ Fernando Centeno Zapata, Salomón de la Selva precursor de las luchas sociales en Nicaragua (Le6n, Nicaragua, 1974). Reproduce artículos del período de 1920 en adelante; Instituto de Estudios del Sandinismo, El sandinismo; documentos básicos (Managua, 1983), recoge algunas de sus colaboraciones en favor de la causa de Sandino. Estos son aspectos muy poco estudiados en SS, autor en general descuidado por la hispanística. Ameritaría varias tesis doctorales y no las menos interesantes en literatura comparada. ${ }^{17}$ Dos ensayos: Julio César y Alejandro Hamilton (León, Nicaragua, 1971), 110.

${ }^{18} \mathrm{Ibid}, 26$.

19 "Los dos partidos efectivos de Nicaragua" [Art. de 1928], en Instituto de Estudios del Sandinismo, op.cit., 238. 
esa novela extrañísma, monumento de saberes clásicos, poema, parábola, Ilustre familia (1952), que no ha sido estudiada en su relación con las nuevas formas que el género novelesco ha adquirido en las letras hispánicas.

Sus escritos póstumos, Dos ensayos: Julio César y Alejandro Hamilton, reflejan una desengañada filosofía política: "En política todo es incierto, precario ${ }^{30}$. Vana ilusión que el pueblo elija directamente a sus gobernantes. Las rebeliones para botar "a los tiranos" han desembocado siempre en tiranías de la misma calaña cuando no en peores"21. Solución: elaborar un nuevo tratado del príncipe, un Maquiavelo adaptado a los nuevos tiempos. Es preciso orientar al buen tirano, apartarlo de los excesos, del robo, de la lascivia, de la crueldad, de la baja envidia. "Toda pasión, excepto la pasión por el poder y el ansia de riquezas, es efímera" ${ }^{922}$. De ánimo templado, guiado sólo por la inteligencia, tendrá por fin el bien de su pueblo, no por afán altruista, sino por egoísmo: así afirmará su poder. Pueblos felices, prósperos y en orden, huyen de rebeliones ${ }^{23}$. Es lo que persiguen los Dos ensayos.

El ensayo de Salomón de la Selva, que va desde el artículo periodístico hasta la semblanza y la biografia, se expande ricamente en apostillas, reflexiones, lecciones, moralejas, ejemplos y comentarios, que hacen su prosa variada, interesante, gustosa de leer. Es lastimoso que no se haya recogido en libro la mayoría de sus trabajos. Según Ernesto Mejía Sánchez, sólo con sus escritos periodísticos de los años 40 "se podrían formar volúmenes"

\section{EDELBERTO TORRES (1988).}

Cultiva el ensayo biográfico y el político. Sus trabajos mayores, dedicados a Dario, Gómez Carrillo y Sandino. Expulsado del Instituto Pedagógico (centro de secundaria) regentado por los Hermanos de las Escuelas Cristianas, por un discurso anti-imperialista (1917), peregrina, como modesto trabajador, por Centroamérica. Se asienta en Guatemala, donde hace carrera en el magisterio. Nacionalista de la primera hora, se forma en la ideología de los grupos liberales demócratas, unionistas, de orientación masónica y teosófica (Sofonias Salvatierra, Salvador Mendieta), en su patria y en Guatemala, en cuya evolución política y social participa (Arévalo, Arbenz). Su pensamiento se radicaliza; a partir de los años 40 , colabora en varios intentos de derribar la dictadura instaurada en su

\footnotetext{
${ }^{20}$ op.cit., 25.

21 op.cit., 25.

22 op.cit., 96.

${ }^{23}$ Luis Alberto Cabrales resume las ideas pedagogicas de SS en sus grandes poemas: "Paideia en Salomón de la Selva" (Managua: Educación, Año 3, No. 7, mayo 1959). Lo mismo podria hacerse con las ideas politicas de Salomón.

${ }^{24}$ Ernesto Mejía Sánchez, "Salomón de la Selva", Homenaje, 86. Antes había dicho: "La obra de Salomón de la Selva está desperdigada por diarios y revistas de los Estados Unidos, Cuba, México, Centroamérica y en algunos países de Suramérica”, 81.
} 
patria. Su magisterio sobre los movimientos revolucionarios contemporáneos del Caribe y Centroamérica, es ampliamente reconocido.

A Darío, su pasión más antigua, dedica su obra magna: La dramática vida de Rubén Darío ${ }^{25}$. Adopta las técnicas de la biografía novelada, que expone André Mauroi $\mathrm{s}^{26}$ : relato lineal, cronológicamente ordenado, monólogos y diálogos imaginarios, descripciones, estilo indirecto libre. Su escritura se mantiene dentro de los cánones del postmodernismo: elegancia, claridad, vocabulario culto, cierto tono discursivo. Con el tiempo, los rasgos "novelescos" han ido desapareciendo por influjo de las exigencias eruditas de objetividad: transcripción directa de los testimonios y no "novelación" de sus contenidos ${ }^{27}$. En otros trabajos no olvida estudiar la critica social en el pensamiento dariano ${ }^{28}$. En Sandino y sus pares estudia las vidas paralelas de quienes, como Sandino,

... lucharon por la independencia, por la libertad, por arrojar del suelo patrio a algún invasor o por abolir privilegios detentados por oligarquías explotadoras ${ }^{28}$.

El modelo es Sandino, del cual se propone dar "el retrato nítido", "el sentido de su lucha y de los frustrados proyectos que tenía para realizarlos después de la guerra de liberación" ${ }^{30}$. El estilo, siempre elegante, se hace más austero, más apretado y justo. A la manera de Plutarco, interrumpe el relato con comentarios sentenciosos, en los cuales rezuma su visión del mundo de maestro ejemplar.

\section{LUIS ALBERTO CABRALES (1901-1974).}

Como a Edelberto Torres, los Hermanos de las Escuelas Cristianas le dan una buena formación francesa. Cabrales se ubica dentro del pensamiento conservador. Político, historiador, poeta, crítico literario, periodista incisivo y temible en la polémica. Estudia en Francia, donde se identifica con el Grupo de Vanguardia. Su estilo, diáfano, es lo más cercano que tenemos a una prosa clásica francesa. Su ideologia es neta y tajante. Aborrece la sociedad liberal burguesa dominante. Para mejorar la condición de las masas urbanas y

\footnotetext{
${ }^{25}$ 1a. ed., Guatemala, 1952. La última, San José, Costa Rica, 1979. Cinco ediciones. Suerte rara para un libro nicaragüense de esa época.

${ }^{26}$ Maurois sistematiza sus conceptos en Aspects de la Biographie (Paris, Grasset [1930], que son conferencias dictadas en 1928. Edelberto Torres confiesa haber sufrido la influencia de ésta, que pudo conocer en su versión original, o en la traducción de la editorial Ercilla (Santiago de Chile) que circulo profusamente por Hispamérica.

${ }^{27}$ En su Enrique Gómez Carrillo: el cronista errante (Guatemala, 1956), esa manera de biografía novelada se mantiene inmodificada.

28 "Rubén Darío poeta civil y social", Flecha, Managua, febrero 4 y 5, 1949. Reproducido en Nuevo Amanecer Cultural, 421 y 423, Managua, 30 de julio y 20 de agosto de 1989.

${ }^{29}$ Sandino y sus pares (Managua, 1983), 9-10.

${ }^{30}$ op.cit., 9.
} 
campesinas, cree necesario volver a un sistema de patriarcado patricio, similar al que predominaba en la colonia. La educación de los campesinos, por ejemplo, debe entregarse a los misioneros católicos, para que emulen la educación que dieron a los indígenas los franciscanos en el sigloXVI. Defensor de la tradición hispánica, no teme defender la Inquisición: "en la mismísima época en que las llamas inquisitoriales, bellas y magníficas, iluminaban la Península, el pensamiento español fulgía tan esplendoroso como en los mejores tiempos de Grecia y Roma ${ }^{n_{31}}$. Puede calcularse el efecto que causarian en los contempráneos afirmaciones de esta índole. Si a esto se agregan sus proclividades fascistas y su activa participación en favor del régimen de Somoza, no sorprenderá que haya ganado prestigio de "reaccionario" a ultranza, de enemigo de las ideas liberales.

Personalidad muy compleja, como observa Julio-Valle-Castillo, se "debatió, agonizó en una viva contradicción" ${ }^{32}$. Razón y pasión es su dilema: razón que se expresa en una prosa límpida, tersa; pasión, que desborda el estilo en ironías, sarcasmos, en comentarios sardónicos. Su visión es de moralista, que anhela cambiar, con el cauterio de sus escritos, una realidad que no se compagina con la imagen ideal que lleva en su alma. De esa confrontación surge un yo, una sensibilidad, que parece a flor de piel, y que se expresa en anhelos, nostalgias, suaves melancolías. Como ensayista, ha dedicado tiempo a temas -históricos y literarios, en los cuales, Rubén Darío es tópico central. Importante es su estudio del pensamiento antiimperialista expresado en la poesía hispanoamericana, en la que analiza y antologa poemas de, entre otros, Neruda, Nicolás Guillén, Alberti, Carrera Andrade, Ernesto Cardenal, y del propio Cabrales ("Oda a los proletarios hispanos") ${ }^{33}$. Su pensamiento en torno a Dario se mantiene en un equilibrado aprecio, aún en la época en que los vanguardistas se manifestabann bulliciosamente antidarianos. Su breve biografía del poeta es modelo de mesurada erudición ${ }^{34}$. En un trabajo de esos mismos años, Cabrales defiende a Darío de una crítica que trata de menoscabar los valores de su obra, a fin de exaltar glorias locales, que el crítico considera inferiores a Rubén ${ }^{35}$.

\section{MOVIMIENTO DE VANGUARDIA}

En plena guerra sandinista, inician sus actividades los muchachos, muy jóvenes, del movimiento, grupo o generación de vanguardia. Integrado por

\footnotetext{
31 "Lanzas por la Inquisición”, Nuevos Horizontes, 6 (Managua, septiembre, 1942): 48. 32 "Cabrales: ideólogo del Movimiento de Vanguardia", Nuevo Amanecer Cultural 428 (Managua, febrero 4, 1989): 4.

${ }^{33}$ Polttica de Estados Unidos y poesta de Hispano América (Managua, 1958).

${ }^{34}$ Rubén Darto: breve biografta (Managua, 1964).

${ }^{35}$ Provincialismo contra Rubén Darto. (Managua, 1966).
} 
estudiantes del Colegio Centroamérica, regentado por los jesuitas, se forman bajo la influencia de una personalidad eminente: el padre Jaime Castiello, Posteriormente, se agregaría el influjo de José Coronel Urtecho, que aportará sus experiencias norteamericanas, y de Luis Alberto Cabrales, transmisor de la poesía vanguardista francesa y de las ideas políticas de Charles Maurras y Leon Daudet. Ideales estéticos del grupo:

Ruptura completa con el modernismo y sus epígonos, libertad formal, versolibrismo, predominio de la imagen, adaptación a sus propias necesidades expresivas de los experimentos poéticos realizados en Europa, Norte y Sur América. Los aportes del surrealismo, del ultrásmo, de las "escuelas de vanguardia" en general son acogidos con entusiasmo. La pirueta y la acrobacia verbal, el humorismo y la burla corrosiva son sus armas en la lucha que entablan contra una literatura que sienten periclitada"36.

En política, en sus comienzos, simpatizan con la lucha antiimperialista de Sandino. Su actitud antiburguesa tiene un sesgo más bien literario que estrictamente politico-social ${ }^{37}$.

La muerte de Sandino significa un enorme hiato en la historia del país:

La tiniebla que sobrevino sobre Nicaragua a partir del asesinato de Sandino, crimen de 1934, se prolongará durante un cuarto de siglo. En el transcurso de ese lapso, Nicaragua se mantendría ideológicamente a nivel de la caverna ${ }^{38}$.

Los jóvenes vanguardistas, conforme a los idearios neo-nacionalistas que florecen en Hispanoamérica y en España, se adhieren a la estrella en ascenso del general Anastasio Somoza García, de cuya campaña política se convierten en ideólogos. Algunos se desengañan pronto y se hacen activos antisomocistas.

Es importante destacar que este grupo de jóvenes vanguardistas de los años 30 (José Coronel Urtecho, Pablo Antonio Cuadra, Joaquín Pasos, Alberto Ordóñez Argüello, José Román, Manolo Cuadra, etc.), prosigue su educación literaria e ideológica, contribuyendo poderosamente a impulsar una literatura nacional. Algunos, hasta hoy ${ }^{39}$. Lo importante, además, es que, por la acción de estos jóvenes, las letras nicaragüenses ingresan decididamente en la

${ }^{36}$ F. Coloma, op.cit., 16.

${ }^{37}$ F. Coloma, loc.cit. Ver además un excelente análisis de este punto en Sergio Ramírez, "El concepto de burguesía en dos noveletas", Revista del Pensamiento Centroamericano 150 (Managua, enero-marzo 1976): 95-97.

${ }^{38}$ Carlos Fonseca, "Viva Sandino", Obras, 2 (Managua, 1982), 85.

${ }^{39}$ Sobre el movimiento de vanguardia, el trabajo de Jorge Eduardo Arellano, El movimiento de vanguardia de Nicaragua (Managua, 1969), es de imprescindible consulta. A este movimiento dedicó Arellano su tesis doctoral, que permanece inédita. Existe abundante bibliografía sobre este grupo, sin mencionar lo que han escrito los propios protagonistas: P.A. Cuadra, José Coronel Urtecho, etc. 
modernidad ${ }^{40}$. Esto, y su acción sobre las nuevas promociones, con las cuales conviven, a quienes influyen y por quienes son influidos, son fenómenos a ser tenidos en cuenta.

\section{JOSE CORONEL URTECHO (1906).}

Es quizás el escritor más brillante, más personal y contradictorio que han producido las letras nacionales. No repetimos lo que otros han estudiado, y bien, de su influencia en el Movimiento de Vanguardia, su intervención en la política, de sus ideas reaccionarias, en aquella época, de su apoyo a Somoza. Si en política -hoy está totalmente instalado en el movimiento sandinista-ha evolucionado, aunque reconoce haberse equivocado casi siempre, si nosiempre, su pensamiento esencial ha permanecido fundamentalmente el mismo, a través de estos largos accidentados cincuenta años, por él vividos plenamente como político-ya lo dijimos-, como poeta y hombre de letras - lo es esencialmente-, como contemplador e intérprete de la historia de su país, como habitante de las márgenes del Río San Juan — convierte el río en metáfora de su vida-, como hombre religioso que busca la comunión con Dios.

Para José Coronel Urtecho el mundo es un laberinto, un conjun to abigarrado de signos, al cual dotan de sentido el pensamiento y la creatividad del hombre. Es la función de los intelectuales: "los intelectuales, son nada más, o si se quiere, son nada menos, los que dan sentido y valor a la realidad"41. La obra de arte, esa "trampa de cazar sombras"42, crea una realidad paralela a la realidad objetiva:

La literatura no se propone dar una idea de las cosas, ni un informe sobre cllas, sino una equivalencia literaria sobre las cosas mismas, reales o imaginarias. Aunque equivalgan a nuestra realidad ordinaria y corriente, constituye en sí misma otro tipo de realidad o nos entrega si se quiere la misma realidad en otro plano de la realidad"43.

Si el mundo, una voltijeante esfera de incitaciones, es mudable, lógico es que el artista y sus obras cambien. La obra de arte -dice en carta al padre Angel -nunca podemos verla como cosa objetiva y acabada, sino siempre la juzgamos

\footnotetext{
${ }^{40}$ Ver Fidel Coloma, op.cit., 16 y ss, en donde se muestran estos traslapes generacionales más en detalle.

${ }^{41}$ José Coronel Urtecho Tres conferencias a la empresa privada. Y Epllogo en memoria de Joaquin Zavala Urlecho (Managua, 1974), 69.

${ }^{42}$ Emilio del Río, "La correspondencia de los poetas" (Managua: Revista del Pensamiento Centroamericano 150 (enero-marzo 1976): 63.

${ }^{43}$ Tres conferencias ..., 31-32.
} 
subjetivamente y en proceso, comparándola con nuestra intención anterior y nuestro ideal futuro" ${ }^{{ }_{44}}$.

Obra en proceso, pensamiento en proceso, en un constante esfuerzo por acercarse a las realidades esenciales - del mundo natural, de la historia humana, del hombre individual que la refleja-, tras las cuales está la nada. En un mundo trascendente, está Dios: "el vacío infinito del que Dios ha sacado y seguirá sacando todas sus criaturas" ${ }^{{ }_{45}}$. A esa nada lanza el artista su "trampa de sombras" para crear, símil de Dios, sus creaturas artísticas". Por eso concluye Coronel: "hay que bañarse diariamente en la nada, darse, de ser posible, una zambullida imaginaria en sus profundidades y volver renovado a la vida ${ }^{46}$. Este heroísmo existencial que Coronel exige al artista, al intelectual, descansa en una confianza inconmovible en la existencia de Dios y en la posiblidad para el hombre de comunicarse con la divinidad. Por eso no encontramos en Coronel la tragedia metafísica de ausencia de la fe que hallamos en Unamuno, a quien admira, ni tampoco esos períodos de sequedad de alma, momentos angustiosos en que se desespera de alcanzar a Dios. En carta al padre Angel, expresa su temor de enfrentarse a esa terrible noche oscura del alma.: "en su dolor veo una profundidad que yo nunca he conocido. Tal vez por eso no llegaré jamás a ser poeta... Prefiero no sufrir a ser poeta (Ya ve hasta dónde soy cobarde) $)^{m_{47}}$.

Estos son algunos de los pensamientos que encontramos en los ensayos de Coronel. Como el mundo es mudable,lo que capta en él el intelecto son contradicciones. Por ejemplo, ve el mestizaje hispanoamericano como una polaridad en tensión inestable entre lo indígena y lo hispano. En Darío encuentra esa polaridad su equilibrio: "el feliz equilibrio del rico mestizaje nicaragüense del propio Rubén ${ }^{m 88}$. El artista representa la cultura de un país o un continente. Así Poe y Whitman son "los dos extremos o polos estéticos de la poesía continental americana"19. Polaridad que se manifiesta en la historia de Centroamérica y de Nicaragua en la contraposición entre la clase comerciante y la clase o estamento intelectual. Quienes han decidido la suerte de la región

\footnotetext{
44 Emilio del Río, loc.cit. Se nos perdonarán las extensas citas de Coronel. No conocemos un estudio general sobre el pensamiento coroneliano. Quizás éstas, recogidas de una manera un poco impresionista y al azar (no es fácil recoger la extensa bibliografía de y sobre Coronel), resulten útiles para los lectores avisados. Véase el interesante trabajo de Carlos Chamorro Coronel, "El humanismo de José Coronel Urtecho" en el mismo nú mero de la Revista del Pensamiento Centroamericano. Establece una relación entre las ideas de Heidegger y las de Coronel, que abre, a mi juicio, inéditas vías para penetrar en la compleja, matizada, no pocas veces contradictoria vision de Coronel Urtecho.

45 "José Coronel Urtecho siendo pintado por Dieter Masuhr o autorretrato con pintor" en Prosa reunida (Managua, 1985), 251.

${ }^{46}$ Loc.cit.

${ }^{47}$ Emilio del Río, op.cit., 64.

${ }^{48}$ Tres conferencias..., 113.

${ }^{49}$ Loc. cit.
} 
han sido los primeros, que sólo en contados casos (Guatemala) han entrado en alianza con los intelectuales para ver manera de dar un sentido al desarrollo histórico. La mayor parte del tiempo, según él, han sido motivados por las apetencias económicas o por un oscuro afán de poder, despojado de norte o guía intelectual ${ }^{50}$.

El intelectual tiene el deber de interpretar ese mundo que obedece más a fuerzas ciegas que inteligentes, corriendo siempre el riesgo de equivocarse. Un factor influyente, que ayuda a la interpretación, es la tradición, que se manifiesta en la mentalidad colectiva de una comunidad. Así la ideología comerciante de Granada, conservadora, frente al liberalismo leonés. Esta mentalidad se transmite en el contagio familiar, donde puede adquirir ribetes singulares. En este plano, el análisis de Coronel alcanza gran finura y penetración, como en el estudio biográfico psicológico que dedica a Joaquín Zavala Urtech ${ }^{51}$.

En su estilo Coronel procede por aproximaciones. Trata de captar la complejidad del mundo real y de expresarlo en párrafos también muy complejos, que él mismo siente enmarañados y necesitados de explicación.

Son frecuentes en sus escritos estas confesiones. Explicar la contradicción que observa entre lo comercial y lo cultural, lo llevó a sucesivas determinaciones que siente no aclaran la esencia del fenómeno. Hasta que concluye: "Es necesario, por consiguiente, no enredar más el lío en que yo mismo me he enredado... ${ }^{{ }^{52}}$. Enredo que no hace más que reflejar la complejidad enmarañada de la realidad objetiva: "por enredados que nos encontramos en la maraña política-económica de la vida nicaragüense ${ }^{63}$. En ocasiones, el escritor mismo se desenreda. Después de una larga explicación en que trata de definir la perspectiva desde la cual Darío miraba a Europa, termina Coronel, no sin humor: "Simplificando el laberinto del párrafo anterior, basta decir que Rubén contemplaba Europa desde París ${ }^{{ }{ }_{54}}$. El problema es que luego sigue introduciendo acápites explicativos que contribuyen a la "poderosa tiniebla", como diría Borges.

Lo importante es que el pensamiento no es confuso, ni mucho menos la expresión. Se trata de una manera de pensar por sucesivos acercamientos a una realidad que se contempla desde múltiples perspectivas, cada una de las cuales genera su propio discurso, todos los cuales se imbrican y entrelazan en una

${ }^{50}$ Tres conferencias ... Véase además: Reflexiones sobre la historia de Nicaragua: de Gainza a Somoza (Managua, 1962), dos tomos. La vocación histórica de Coronel Urtecho se manifiesta temprana. Ver "Historia de Nicaragua". Revista de la Academia de Geografía e Historia de Nicaragua. año 1, No. 2 (Managua, diciembre de 1936). Reproducido en Revista del Pensamiento Centroamericano, Número citado, pp. 122-152.

${ }^{81}$ En Tres conferencias ...

${ }^{52}$ "Epílogo...", en Tres conferencias, 68.

${ }^{53}$ Op.cit., 103.

${ }^{64}$ Tres conferencias..., 120. 
trama muy compleja, ricamente dotada de sentido. Llamaría proteico el discurso expositivo de Coronel, escritor barroco, hermano, en algunas prosas, de Lezama Lima. En oportunidades recurre al aforismo: el pensador se expresa en párrafos breves, a ratos en oraciones aisladas, que apuntan a aspectos, aparentemente contradictorios, del tema central.

\section{PABLO ANTONIO CUADRA (1912).}

Si José Coronel Urtecho es la inteligencia inquieta, algo anárquica, atraída por los mil aspectos de lo real, desflorando temas, sugiriendo, en una búsqueda alegre, pródiga de sus dones ${ }^{55}$, Pablo Antonio Cuadra-PAC-según susiniciales consagradas - es el intelectual sobrio, que se mantiene, austero, dentro de grandes líneas de pensamiento, sumergiéndose cada vez más en el hondón de las realidades que intuye. Ambos son sociales, amigos de sus amigos. Coronel tiende, socráticamente, a alternar con grupos reducidos de almas fraternas, dirige en revistas (Cuadernos del Taller San Lucas, El pez y la Serpiente), o en el periódico (LaPrensa, La Prensa Literaria) ${ }^{56}$. A través de este úl timo suplemento dominical, ha ejercido un magisterio decisivo en las letras y en la cultura nicaragüenses: "No hay poeta nacido después de 1925, que no lleve, en bajo o alto relieve, huellas de su paso, alientos de su tesitura, astillas de su ancha madera nacional", señala Guillermo Rothschuh Tablada ${ }^{57}$. PAC es hombre sistemático, disciplinado, laborioso, estudioso. Su ideal es el monje, que ora et labora, en su celda, en el huerto, o en la comunidad de religiosos y de fieles. José Coronel Urtecho, que puede simpatizar con esas conductas (de hecho, ha vivido largos años, con su familia, aislado en las regiones del río San Juan), tiene (ha tenido) estallidos vitales que lo acercan más al jocundo Arcipreste de Hita que a un monje asceta.

Reviste cierta importancia conocer la idiosincracia de estos dos hombres de letras que, sin lugar a dudas, han marcado con su influjo la literatura nicaragüense.

55 “Siempre ha poseído un potentísimo olfato de adivino y en gran parte su obra ha sido reducida por esta condición suya de adelantarse a sí mismo!". Pablo Antonio Cuadra, Torres de Dios (2a. ed., Managua, 1985), 159.

${ }^{56}$ Aunque a veces desespere de lograr una auténtica comunicación con las masas: "Yo le decía a Guillermo Rothschuh: el poeta escribe para algunos amigos. Lo que se cocina después, lo que resulta de un éxito, lo que puede llamarse fama y que algunos, ilusos, llaman glorias, se teje a veces de resonancias tan falsas, de reales incomprensiones $e$ incluso de malentendidos que producen una infinita soledad" (Homenaje ..., 23). A pesar de la desesperanza que testimonia esta cita, PAC persiste en su faena de difusión del pensamiento, guiado por su auténtica vocación de educador.

57 "Pablo Antonio Cuadra y la poesía nicaragüense", en Ciencias dela Educación 5 (Managua, 1975): 64 . 
PAC, como digo, es hombre de pensamiento y de acción. La política le atrajo (se le impone). En sus años mozos del grupo de vanguardia, asimiló el pensamiento tradicionalista hispánico, particularmente en Argentina y luego en México y España. Dentro de la ideología del grupo de vanguardia (él contribuyó más que nadie a remarcarlo), preconizó desde temprano una interpretación de la sociedad, la cultura y la política, apoyada en el hispanismo y en el aporte indígena. El mestizaje es la realidad esencial de Nicaragua y Latinoamérica, la matriz que conforma la manera de ser de nuestros pueblos. La herencia hispana, católica, es vocación de universalidad; el indio aporta la visión telúrica ahincada en una cultura en íntima simbiosis con lo terrígeno.

De esa línea mestiza viene Dario, "que proclama en sí mismo, contra todos los complejos y prejuicios de su tiempo, el orgullo de ser mestizo" ${ }^{\text {"8. }}$. Loimportante es ver cómo, a través de qué modalidades, de qué signos, se transparenta en el proceso creador de Rubén, el mestizaje, el aporte indio. Estudiando "Tutecotzimí, observa que en la adjetivación del poema se trasluce una nueva (vieja) manera de ver, que estiliza los objetos de la realidad en sus rasgos esenciales. Tal como los indios hacían cuando pintaban la fauna de su tierra en sus vasijas de barro:

Con tres palabras, en un juego de sonidos, a veces con la pincelada de un solo adjetivo que traza estilizadamente el perfil esencial del animal, vemos aqui al viejo indio chorotega o nagrandano de la cerámica policromada regresar, por la palabra de Rubén, el mestizo, a la literatura universal ${ }^{n_{58}}$.

Incluso en el lenguaje, en la sintaxis del español de Darío, cree Pablo ver la huella de la sintaxis del náhuatl. Es la tarea que se propone Pablo Antonio en El jaguary la luna (1959), maravilloso "librojícara", en que el glifo, el pictograma, de raíz indígena, y el lenguaje poético contribuyen a recrear un mundo mítico, en que las ansias, aspiraciones, tribulaciones y combates del nicaragüense actual se embeben de una atmósfera india alucinante.

En El nicaragüense $e^{60}$, Pablo Antonio quiere dilucidar los rasgos esenciales de la tierra de Nicaragua y de su habitante. Rastrea las modalidades que adquiere el nicaragüense como resultado del interflujo de la herencia hispanoindígena y del factor geográfico. Incluso ciertas idiosincracias, tales como la tendencia trashumante, reflejarian las inclinaciones de aquellas lejanas tribus errantes que llegaron a Nicaragua desde la altiplanicie mexicana.

Define la realidad nicaragüense por el dualismo, que se arraiga en el mestizaje. Su historia transcurre en un constante oscilar entre dicotomías: exotismo, espíritu de aventura, frente a permanencia; militarismo y dictadura, frente a civilismo y democracia, etc. Incluso en un mismo sujeto coinciden

\footnotetext{
${ }^{58}$ "Rubén Darí y la aventura literaria del mestizaje", en Aventura literaria del mestizaje y otros ensayos, (San José, Costa Rica, 1988), 89.

${ }^{59}$ Op. cit., 90.

${ }^{60}$ Managua, 1967.
} 
núcleos valorativos opuestos, de manera que "valora con la tabla del dominador y con la tabla del dominado ${ }^{n_{61}}$. Es un concepto muy complejo, que vale la pena aclarar con una cita del propio Pablo:

Pero yo llamo "dualidad", sobre todo, a la inmanencia de estas situaciones. A convivir las antítesis. Dualidad como desgarradura interior de ideologias, sicologías, concepciones del mundo y valoraciones humanas. En nuestro proceso de mestizaje y en nuestra historia se fueron formando estratos su perpuestos: de formas sociales que organizo el dominador, y de escombros de las anteriores indigenas; de clasificaciones y criterios clasistas, de estructuras familiares, de sistemas y niveles econónomicos, de pastoral religiosa, etc. ${ }^{62}$.

A esto se suma la influencia telúrica: Nicaragua es país puente, región de tránsito para pueblos innumerables. Es también tierra de volcanes y terremotos. Esto da una cualidad singular al tiempo. El nicaragüense vuelve la espalda a la tradición, volcado al futuro, acicateado por la "febrilidad destructora del tiempo"6s.

El tiempo es el gran destructor: roe la palabra, la fama incluida. El escritor se expresa en lucha contra el tiempo. Por la palabra aspira a perdurar. Y esto sólo se logra por la comunicación con el pueblo. El poeta vibrará con el alma popular, a la que, por medio de la palabra, nutrirá de muchas dimensiones y sentidos. Melancolía, esperanza, fe:

Cacrá la lluvia del tiempo, dejará la luna de iluminar el muro y la palabra pasará al olvido. Pero que la palabra sea comunión, que existan tantas y tan valiosas personas capaces de sostener la palabra, de repuntarla con nuevo trazo, de renovarla con nuevo espíritu, jah!, entonces el autor de una palabra entre otras ya no importa; lo que importa es que un pueblo habla, lo que importa es que la llama del espíritu ha encendido el don de su lengua, que un pueblo se expresa y no calla, que un pueblo protesta y no se somete, que un pueblo es poeta de su destino, poeta en el sentido etimológico de "poietes", el hacedor ${ }^{64}$.

La religión (el catolicismo) es elemento de comunión. El tema religioso es constante en su poesía: "Pablo Antonio Cuadra es el que ha tenido más temas religiosos en su poesía" "65, dice Ernesto Cardenal. Y Gloria Guardia de Alfaro: "El sentimiento religioso constituye el nervio mismo donde se apoya el centro espiritual de Cuadra" ${ }^{\text {"66 }}$. No es que en su prosa constituya tema, propiamente;

\footnotetext{
${ }^{61}$ Aventura literaria del mestizaje, 29.

62 Ibid.

${ }^{63}$ Op.cit., 30. Dice PAC: "Y siente un exceso de impulso al futuro".

${ }^{64}$ Homenaje nacional a Pablo Antonio Cuadra (León: Nicaragua, 1973), 31.

${ }^{65}$ Eduardo F. Elías, Jorge H. Valdés, "Cardenal: entrevista" Hispanoamérica 48 (1987): 48.

${ }^{66}$ Estudio sobre el pensamiento poético de Pablo Antonio Cuadra (Madrid, 1971), 72.
} 
más bien es un sentimiento difuso, una perspectiva desde la cual interpreta el mundo, la cultura y las letras, que no deja pasar indvertido este factor, aún cuando estudie autores reconocidamente ateos.

Un carácter religioso (de comunidad religada) tiene su idea de la confraternidad de los artistas. Por ello PAC nocree en la aplicación a la historia literaria de una mecánica de las generaciones, yuxtapuestas, sucediéndose como compartimentos estancos. Al contrario, él cree que (como en caso de Nicaragua) diversas generaciones (jóvenes, maduros, viejos) conviven en la historia, se influyen mutuamente: tanto dan los mayores, como reciben de los bisoños. Esto explica los cambios "a veces radicales, que el escritor sufre en su lucha con el tiempo"67.

La prosa de Pablo Antonio en sus ensayos literarios, sociológicos y políticos, es prosa de maestroy de poeta: surge de un pensamien to lógicamente organizado. Apoyada siempre en lo real, sea esto una obra literaria, la historia o una tendencia idológica, organiza en torno a su tópico una fina malla conceptual, que lo sitúa, lo define, lo aclara. Su estilo, tan certero, tan neto, recuerda que hay en Pablo Antonio Cuadra un artista gráfico, un dibujante cuyas líneas van también delimitando la imagen, siempre poética, del objeto a que apunta.

\section{MARIANO FIALLOS GIL (1907-1964).}

Es el maestro por antonomasia, forjador de juventudes, fundador de la universidad moderna en Nicaragua. Más que por la profundidad o novedad del pensamiento, se distingue por la hondura emocional con que hace suyos los conceptos, que traduce en normas éticas de acción. Heredero del liberalismo de occidente, muestra algunos de los rasgos que Cerutti atribuye a esosideólogos ${ }^{68}$ : "profundo sentimiento humanitario y legalista", "humanismo", "indómita valentía, acrisolada honradez, admirable coherencia moral". En ese León de tradición culta y universitaria, se forma Mariano Fiallos, temperado el afán ideológico por una irresistible inclinación práctica.

Funda el grupo PROA (Patria, Renovación, Optimismo, Acción) en 1934, que frente a la coyuntura, asume una actitud muy temperada, orientada más a reformas legales y administrativas que a profundas transformaciones sociales y políticas. Dice Sergio Ramirez definiendo las características del grupo:

Esta falta de planteamientos profundos, de un contenido ideológico renovador, fue lo que quito dimensión y trascendencia en el tiempo al grupo PROA, y sería seguramente lo que determinó su desintegración pocos años después ${ }^{69}$.

${ }^{67}$ Aventura literaria del mestizaje, 48.

${ }^{68}$ A estos liberales de occidente (Emigio Jerez, José Madriz, Félix Quiñones, Mariano Barreto) los estudia Franco Cerutti en un excelente trabajo: "Los liberales doctrinarios de occidente", en Boletin Nicaragüense de Bibliografiay Documentación 60 (Managua, febrero-abril, 1989).

${ }^{69}$ Sergio Ramírez: Mariano Fiallos: biografla. (León, Nicaragua, 1979), 35. 
El grupo se disuelve en 1936 y sus miembros se integran, paulatinamente, al gobierno de Somoza. Queda, sí, en Mariano Fiallos, virtual y poderosa, la inclinación a intervenir en la política práctica y el afán pedagógico de formación y autoformación en círculos de estudio. De lo primero es muestra su gestión en el Ministerio de Educación del cual llegó a ser Ministro, y de lo segundo un intenso programa de lecturas con que completó su cultura general, social y política. Cita Sergio Ramírez al Dr. Rafael Gutiérrez, amigo de juventud de Fiallos:

Con este motivo, conversando al respecto de cómo estudiaban y se docu mentaban "los reaccionarios" mientras los de ideas progresistas viviamos aislados y hasta sin conocernos y menos aún para hacer prácticas de discusiones, un día decidimos formar un grupo de estudio ${ }^{70}$.

Productos de esos estudios son numerosos artículos de polémica política literaria que Mariano publica en Managua y León. Se hace famoso por el estilo brillante, humorístico, irónico, con que defiende, sin miedo ni tapujos, sus ideas. Pero es cuando acepta la Rectoría de la Universidad Nacional de Nicaragua, que bajo su dirección llegó a ser au tónoma, cuando afirma su prestigio como caudillo intelectual de su patria y cuando publica, en periódicos y revistas, una copiosa serie de artículos sobre educación y literatura ${ }^{71}$.

$\mathrm{Al}$ asumir como Rector (cargo que atendió desde 1957 hasta su muerte, en 1964), encuentra una universidad enredada todavía en las telarañas coloniales.

Mariano le impone un nuevo espíritu, destaca la importancia y la responsabilidad de la docencia, estimula la participación de los estudiantes en la gestión universitaria, promueve la introducción del método científico en las actividades académicas, remoza laboratorios y bibliotecas y, sobre todo, enlaza la Universidad con la vida social, económica y cultural del país.

Preconiza un concepto humanístico de la universidad, a la que concibe centrada en la formación integral de alumnos y profesores, no como un instituto tecnológico que prepare profesionales incultos, ni tampoco como un núcleo de alta ciencia vuelto de espaldas a la realidad de su pueblo: "Nuestro concepto de la Universidad es humanístico, esto es, que lo esencial es el ser humano en sí y no la ciencia, la sociedad o el Estado"72.

\footnotetext{
${ }^{70}$ Op.cit., 41.

${ }^{11}$ Recogidos en Humanismo beligerante (1958), A la libertad por la Universidad (1960), Panorama universitario mundial (1961), que resumen su visión del mundo y su posición pedagógica. Crítica literaria: León de Nicaragua: campanario de Rubén (1958), Salomón de la Selva: poeta de la humildad y la grandeza (1963), Crónicas de viaje: De nueva Orleans al cercano Oriente (1964). Relatos y poemas: Horizonte quebrado: cuentos y poesias (1959). Mucha obra suya no ha sido recogida en libro. Véase el estudio de Sergio Ramírez, ya mencionado, para una bibliografía más completa.

72 "Carta del Rector a los estudiantes" (1958) en A la libertad ..., 77.
} 
Humanismo quiere decir enfrentarse, en forma metódica, a la realidad. "Nuestro trabajo debe ser metódico" y real. Nada de escolasticismos, que eso nos ha costado demasiado caro. Nada de pereza para imaginar simplemente una premisa y luego otra y deducir de ambas una conclusión que de antemano ya conociamos $^{\text {77s. }}$.

Formación intelectual de la sociabilidad, de la sensibilidad estética, sobre todo de la moral del estudiante. Y éste es el otro plano desde donde enjuicia el proceso educativo universitario: el de la conducta ciudadana de los egresados. La piedra de toque es saber si no se dejan guiar únicamente por fines mercantiles, y si anteponen a todo el servicio de su pueblo y de su patria.

Es una suerte de heroísmo el que quisiera imbuir Mariano a los universitarios. Una altitud moral que los proteja de los embates de una sociedad mezquina y pragmática, explotadora del débil; proclive al servicio ante los déspotas.

Cree que esto se logrará por la cultura, que inculcará en el individuo una insobornable aspiración de libertad y una voluntad inquebrantable de ejercerla en todos los planos: profesional, cultural, político, económico y social. Pueden parecer algo vagos estos preceptos. Sin embargo, como predicó con el ejemplo, como sacrificó a ellos su precaria salud y por ellos acortó sus días, logró formar una falange de discípulos que continuaran su empeño.

La crítica literaria de Mariano traduce sus variados intereses estéticos. Impresionista, anecdótica, tiende a expresar un estado de ánimo a la vez que plantear problemas existenciales. Sobre todo, describir la poesía ínsita en los rincones de su León provinciano: "Me agrada pasear por los rincones de los barrios silenciosos escuchando las canciones populares de un sub-León desconocido ${ }^{74}$. Azorín, Baroja, Unamuno, Ortega, resuenan por estas páginas que aún conservan frescura e interés.

Pero es como sujeto ejemplar, como orientador de generaciones, que Mariano Fiallos ha impreso huella imborrable en la historia nacional. Fundó "una era en la cultura nicaragüense" ${ }^{\text {"75 }}$.

\section{MANOLO CUADRA (1907-1957).}

Poeta, cuentista, novelista. Primordialmente fue periodista, oficio que ejerció en Nicaragua y Costa Rica, alternándolo con los de soldado, obrero en las bananeras y otros a que lo obligó su vida errante. (Se llamó a sí mismo "un nómada local" "r. Fue opositor al régimen de Somoza, esto lo apartó de la

${ }^{73}$ Op. cit., 80-81.

${ }^{74}$ Leon de Nicaragua ..., 22.

${ }^{76}$ Sergio Ramírez, Op.cit., 199.

76 "Santo y Seña" en El Gran Diario y en Flecha. Monografía elaborada por Libia Chévez Flores et al. (Managua, 1980), 203. 
Vanguardia, que apoyó al general. Somoza lo condenó a destierro, cárceles y relegaciones. Motivados en ocasiones por los escritos humorísticos del poeta en Semana Cómica, donde colaboraban Joaquín Pasos, Gonzalo Rivas Novoa (GE ERRE ENE) y Toño López. Contribuyó a separarlo más de la vanguardia el que, cuando estalla la Guerra Civil Española, Manolo apoyara decididamente, la causa leal. Se convierte en eje de un grupo de escritores y periodistas de izquierda en Managua, algunos de los cuales, adversaban la estética vanguardista: José Francisco Borgen, Francisco Hernández Segura, Amado Amador, Emilio Quintana, Ricardo Zeledón, y otros.

"Manolo Cuadra, el primero de nosotros que se cruzó a la acera izquierda y dio con las señas de la casa del oprimido", afirma Pablo Antonio Cuadra ${ }^{77}$. Así fue: Manolo Cuadra perteneció al Partido Trabajador Nicaragüense ${ }^{78}$.

Manolo deja una enorme producción periodística yensayística desparramada en la prensa de Nicaragua y Costa Rica. De toda ella, muy poco se ha recogido. Santo y Seña eran breves comentarios, intencionados, o sobre faits divers de la vida nacional, siempre apuntados a una crítica del régimen. Obtuvieron gran acogida de los lectores, pese a que el escritor recargaba la crítica a las costumbres, a la abulia de la ciudadanía que aceptaba displicente los desafueros del régimen. "Pueblo gato", lo llama, "que tiene tantas vidas como habitantes, tantos poros como heridas y tanta vitalidad como resignación"79. Lo confronta con Somoza:

Los nicaragüenses, verborrágicos, pantomímicos, emocionales y retóricos, hemos dejado retoñar a un solo Gobierno durante casi un cuarto de siglo. Somoza ha probado saber colocarse más allá de la órbita de sus obligaciones y librarse de la todopoderosajurisdicción popular. Nos ha dado el drama y la comedia, el pan y el palo, el gemido y la carcajada, el veneno y el vino, la plata y el plomo ${ }^{80}$.

Hábil en la imagen pintoresca que condensa un pensamiento, recurre a frecuentes juegos de palabras que hacían las delicias de sus lectores. Como cuando a unos consocios en un negociado, los califica de consucios.

Otro tipo de ensayos, de mayor vuelo literario, salieron de su pluma. Sólo algunos han sido recogidos ${ }^{81}$. Impresionan los dedicados al Gral. Moncada y al

\footnotetext{
${ }^{77}$ Homenaje Nacional ..., 34.

${ }^{78}$ En junio de 1935 asiste a una reunión del Comité Central, en Masaya, como delegado por Managua. Le encomiendan la redacción del Programa político. Véase Carlos Pérez Bermúdez y Onofre Guevara El movimiento obrero en Nicaragua: Apuntes para el conocimiento de su historia (Managua, 1985), 99.

78 "Santo y Seña ...", 240.

${ }^{80}$ Op.cit., 294. Este "Santo y Seña apareció el 13 de agosto de 1955, Flecha.

${ }^{81}$ Hemos logrado consultar: Pablo Antonio Cuadra en Poemas Nicaragüenses" (Octubre, 1934), en José Calatayud Bernabeu, Manolo Cuadra: el Yoy las circunstancias (Managua, 1968), 150-155. "La verdadera guerra podría ser entonces", Nuevos Horizontes 2(1942): 4-7; "De la América a las antípodas". ¿Y a la poesía, qué? Nuevos Horizontes 5 (1942): 17 -
} 
poetaJoaquín Pasos. Se trata de dos retratos post-mortem. Tras la dura máscara del general adivina la voluntad férrea, la independencia de su carácter. Con cuánta ternura esboza un himno mortuorio para Joaquín Pasos, el entrañable poeta fallecido. El estilo es de poema en prosa:

Están los ojos, por dentro, muellemente abandonados. Los párpados los cubren como dos pétalos orlados del musgo mortuorio de las pestañas. El cuello, con la cabeza, se ha doblado un milímetro hacia el lado del corazón (había de haberlo amado mucho para notarlo), y en la frente exangüe, de marfil asesinado, se advierten sin esfuerzo, las señas digitales del eterno sueño ${ }^{82}$.

Ritmo de verso, que recuerda las cadencias de la prosa modernista, escuela de la que nunca estuvo Manolo muy apartado.

Dignos de mención son los trabajos sobre Darío,. En "Rubén Darío emperador" muestra cómo la poesia dariana, ha penetrado tanto en la cultura popular, que algunos de sus versos aparecen en labios del pueblo como refranes. En el otro ("De la América o de las antipodas...") se refiere al debatido tema de si la poesía de Rubén refleja o no lo americano. Manolo sostiene que no y que eso, en plena época del capitalismo burgués que universaliza la cultura, no tiene ninguna importancia ante los verdaderos valores de esa poesía.

Importante es su conferencia sobre Rimbaud, con quien algunos críticos creen que él se identificaba. En carta a Rolando Steiner, fechada en el Hospital del Seguro Social, de San José de Costa Rica (24-II-1957), recuerda un verso de Rimbaud: "Por delicadeza yo perdí mi vida". Manolo se duele de no haber sido él mismo, de no haber dejado desenvolverse su ser auténtico: civilizado o salvaje: "Mi buen corazón me hizo fracasar doquiera, porque no supe sino sentir a través de los otros". Percibe en Rimbaud un "afán de desintegración" que se vuelve en rechazo a la sociedad, a la religión, al arte mismo. Se evade, viaja, revesa sobre las convenciones sociales. Abjura de la poesía a los 17 años, para dedicar los 18 restantes al comercio, a la trata de esclavos. ¿Ese destino ansía Manolo? ¿De no haber llegado a esas negaciones extremas se arrepiente?

Por la humanidad, la gracia del estilo, la irreductible adhesión a la causa de los pobres, Manolo es una de las figuras literarias más atrayentes de las letras nicaragüenses.

21; "Rubén Darío el emperador". Nuevos Horizontes 3 (19942): 9-13; "Memorandum básico sobre el Gral. Moncada", La Prensa, 28-11-1945; En Calatayud, op.cit., 159-161; Tragedialiteraria de Jean Arthur Rimbaud (1945). En Manolo Cuadra, Solo en la compañta (Managua, 1982), 153-161; "Poesía y muerte de Joaquín Pasos", Los lunes de la Nueva Prensa, 27-I-1947. En: Calatayud, op.cit., 162-165.

${ }^{82}$ Calatayud, op.cit. 162. 


\section{Nota final}

Hasta aquí estas notas sobre el ensayo nicaragüense, que consideramos preliminares de este volumen, que exige tratar el tema en su totalidad. Se habrá advertido la singular calidad de esta producción ensayística. Con el aporte de las nuevas generaciones ensanchará su temática, acercándose, cada vez más al estudio rigurosamente científico. Así se avanza hacia la geografía y la biología, con Jaime Incer Barquero. Hacia las disciplinas filosóficas, políticas y sociales, con Julio Ycaza Tijerino, Fernando Centeno Zapata, Guillermo Rothschud Tablada, Carlos Tünermann, Bernheim, Alejandro Serrano Caldera, Pedro Joaquín Chamorro Cardenal, Eduardo Zepeda-Henríquez. Sin ovidar a quienes se mantienen más orientados hacia la literatura, como Ernesto Mejía Sánchez, Ernesto Cardenal, Ernesto Gutiérrez, Mario Cajina Vega. Aunque, en el caso de Cardenal, su acción política se haga cada vez más intensa.

$Y$ en la generación posterior, la del 60, tenemos, en el Grupo de Ventana, a Fernando Gordillo, Sergio Ramírez, Beltrán Morales. En el grupo de la "Generación Traicionada", a Iván Uriarte. Y a personalidades tan acusadas, como Carlos Fonseca, que origina un movimiento ensayístico orientado hacia lo político, histórico y socio-económico. Allí se inscriben estudiosos como Ricardo Morales y Jaime Wheelock Román, para no recordar sino algunos. Como Jorge Eduardo Arellano, cuya labor de polígrafo (poesía, novela, cuento, teatro, ensayo, erudición, crítica de arte) es verdaderamente ciclópea. O como Horacio Peña y José Emilio Balladares, recientemente fallecido.

Y dentro de los últimos, Leonel Rugama, Erick Blandón, Julio Valle Castillo, Alvaro Urtecho, Erick Aguirre, Juan Chow. Sin olvidar a las mujeres: Gioconda Belli, Michelle Najlis, Daysi Zamora, Vidaluz Meneses, Rosario Murillo, Margarita López, que cultivan el ensayo político y la crítica literaria.

Todos son, además, políticos, narradores, poetas, dramaturgos.

Aportan las bases teóricas que ayudarán al país a interpretar su propia realidad y a adoptar las vías que, lenta, sacrificadamente, conducen a su liberación.

Managua, mayo de 1989. 
